\title{
PERFIL DA QUALIDADE DO LEITE EM PROPRIEDADE RURAL DO MUNICÍPIO DE ITAPERUNA, RIO DE JANEIRO, BRASIL
}

\author{
Maíra Barreto NOGUEIRA, Luiz Antonio Eckhardt de PONTES, Hingrid Barbosa de SOUZA, Fernanda \\ Giácomo RAGAZZI \& Juliano Gomes BARRETO*
}

Universidade Iguaçu - Campus V. Itaperuna, Rio de Janeiro, Brasil.

Autor para correspondência: julianobarreto@hotmail.com

DOI: http://dx.doi.org/10.18571/acbm.162

\section{RESUMO}

De forma abrangente o leite é o produto obtido da ordenha completa e ininterrupta em condições de higiene, de vacas leiteiras sadias, bem alimentadas, tratadas e em repouso. A presente pesquisa quali-quantitativa de procedimento técnico bibliográfico apresenta um relato sobre o monitoramento de qualidade do leite ordenhado em propriedades rurais de Itaperuna/RJ, com o objetivo de monitorar a qualidade do leite bovino do referido município, considerando a variação na qualidade do leite e a influência do monitoramento no destino estabelecido para o produto avaliado. As amostras foram submetidas a ensaios químico, microbiológico e físico-químico com uso de equipamento ultrassônico, potenciômetro e kits comerciais disponibilizados pelo laboratório de análises de leite da Universidade Iguaçu Campus V. Os resultados obtidos indicaram a eficiência dos testes realizados para detecção e progressão da mastite subclínica, além da composição do leite e sua variação. Foi evidenciado que os métodos rápidos e práticos de diagnóstico são necessários para o monitoramento do leite. O Somaticell apresenta uma sensibilidade maior e interpretação menos subjetiva quando comparado ao CMT. Além disso, constatou-se a importância da orientação e da realização da prática do pré-dipping e pós-dipping, conforme às diretrizes estabelecidas pelo órgão regulamentador do controle de qualidade.

Palavras-chave: Leite; Qualidade; Monitoramento; Mastite subclínica.

\section{ABSTRACT}

Quality profile of milk in rural property at the city of Itaperuna, Rio de Janeiro, Brasil. In a comprehensive manner, milk is the product obtained in full and uninterrupted order under hygienic conditions, from healthy, well fed, treated and resting dairy cows. The present qualitative quantitative research of technical bibliographic procedure presents a report on the quality monitoring of the milked milk in rural properties of Itaperuna/RJ, with the objective of monitoring the quality of bovine milk, considering the variation on the quality of the milk and the influence of the monitoring at the treatment established for the evaluated product. The samples were submitted to chemical, microbiological and physico-chemical tests with the use of ultrasonic equipment, potentiometer and commercial kits made available by the laboratory of milk analysis of the University Iguaçu Campus V. The results obtained indicated the efficiency of the tests performed for the detection and progression of subclinical mastitis, as well as milk composition and its variation. It was evidenced that fast and practical methods of diagnosis are necessary for the monitoring of milk. Somaticell has a higher sensitivity and less subjective interpretation when compared to CMT. In addition, it was verified the importance of the orientation and improvement of the practice of pre-dipping and post-dipping, according to the guidelines established by the regulator of quality control.

Keywords: Milk; Quality; Monitoring; Subclinical mastitis. 


\section{Biomedica Brasiliensia}

\section{Introdução}

A presente pesquisa quali-quantitativa de procedimento técnico bibliográfico apresenta um relato sobre o monitoramento de qualidade do leite ordenhado em propriedades rurais de Itaperuna/RJ.

De forma abrangente o leite é o produto obtido da ordenha completa e ininterrupta em condições de higiene, de vacas leiteiras sadias, bem alimentadas, tratadas e em repouso (BRASIL, 2011).

Dessa forma, o objetivo desse estudo é monitorar a qualidade do leite bovino ordenhado em propriedades rurais no município de Itaperuna - RJ, e integrar o monitoramento da produtividade leiteira ao programa de Extensão Rural e Universitária do Curso de Medicina Veterinária da Universidade Iguaçu Campus V, Itaperuna- RJ (UNIG).

Neste contexto, justifica-se tal matéria pela variação na qualidade do leite que leva a ocorrência em determinadas ocasiões de descarte significativo ou subaproveitamento do leite produzido na região. Programas de monitoramento visam contribuir para melhoria na qualidade final e consequente redução no descarte do produto e prejuízos causados aos produtores.

A metodologia aplicada foi com base em ensaios químico, microbiológico e físico-químico com uso de equipamento ultrassônico, potenciômetro e kits comerciais disponibilizados pelo laboratório de análises de leite da Universidade Iguaçu Campus V.

As amostras foram coletadas em uma propriedade rural do município de Itaperuna-RJ, se adequando a orientação dos coordenadores e demais membros participantes do Programa de Extensão Rural e Universitária do Curso de Medicina Veterinária da Universidade Iguaçu Campus V responsáveis pelo trabalho de orientação e capacitação dos ordenadores e trabalhadores rurais envolvidos no processo, além de monitoramento veterinário. As amostras após obtidas, serão imediatamente refrigeradas e mantidas a temperatura de $2^{\circ} \mathrm{C}$ à $4^{\circ} \mathrm{C}$, sendo posteriormente enviadas ao Laboratório de Análises de Leite da UNIG, para processamento das análises laboratoriais.

\subsection{Conceito de Leite}

De acordo com a Instrução Normativa $N^{\circ}$ 62, do Ministério da Agricultura, Pecuária e Abastecimento denomina-se leite, sem outra especificação, o produto normal, fresco, integral, oriundo da ordenha completa e ininterrupta (BRASIL, 2011).

O leite é um alimento com extenso valor nutritivo e muito consumido pela população mundial, porém, é também, um bom meio de cultura para muitos microrganismos, assim, a existência de problemas relacionados a condições higiênicas deficientes durante os processos de obtenção, manipulação e conservação vêm sendo considerada como uma das principais razões para a ausência de qualidade do leite (ROSA \& QUEIROZ, 2007, p. 423).

\subsection{Propriedades do Leite}

A composição do leite pode diferir, mas uma forma padrão deve conter: $87,1 \%$ de água, $3,4 \%$ de proteínas, 3,9\% de gordura, 4,9\% de carboidratos (açúcares) e $0,7 \%$ de sais minerais, além de outras vitaminas (PRATA, 2001).

De forma mais inclusiva, é qualificado como uma mistura complexa, constituída por várias substâncias como água, proteínas, gorduras, carboidratos, minerais e vitaminas, consistindo um alimento humano bastante próximo à exatidão. No entanto, as mesmas características que o tornam um alimento de grande importância nutricional, garantem o crescimento de microrganismos tornando sua resistência limitada pela presença e aumento de microrganismos indesejáveis, os quais fomentam, entre outras, alterações físico-químicas no mesmo (SOARES et al, 2010). 
A quantidade do leite produzida e sua composição apresentam variações ocasionadas por diversos fatores, tais como alimentação, doenças, período de lactação, ordenhas, fraudes e adulterações (BERSOT et al, 2010, p. 645-652).

Qualquer substância que não faça parte da composição do leite bovino é classificada como estranhas e estando presentes, podem causar danos à saúde humana. A adição de substâncias estranhas ao leite está relacionada a fraudes que podem ocorrer desde a fonte de produção até a fase de comercialização. Tais substâncias são classificadas de várias maneiras, de acordo com a finalidade de seu uso. Pode-se tratar de substâncias conservadoras e/ou inibidoras, de substâncias redutoras da acidez ou ainda de substâncias reconstituintes da densidade (TRONCO, 2003).

O Ministério da Agricultura, Pecuária e Abastecimento - MAPA, através da Instrução Normativa $\mathrm{n}^{\circ}$. 62, regulamenta o padrão de identidade e qualidade do leite, incluindo manejo de ordenha, resfriamento na propriedade, transporte em grande quantidade, parâmetros físicoquímicos, microbiológicos e contagem de células somáticas, o que aumentou o nível de exigência nas propriedades e nas indústrias da área (BRASIL, 2011).

\subsection{Manejo, etapas e higienização na ordenha manual}

A ordenha é uma atividade que requer atenção e cuidado devido a sua influência na produção do leite, na qualidade e na saúde dos animais. Todo o cuidado durante a ordenha envolve a higiene não só dos animais como a do local, dos utensílios e do ordenhador (RIBEIRO e BRITO, 2012).

Segundo a Embrapa a ordenha manual deve obedecer aos seguintes critérios: conduzir a vaca cuidadosamente para ordenha; prender a cauda e as patas da vaca; prender o banco na altura do quadril; lavar as mãos e o antebraço com auxílio de escova e sabão e secá-los com uma toalha limpa; examinar e descartar os três primeiros jatos de leite, em caneca de fundo escuro; lavar as tetas com água corrente e tratada; e secar as tetas com papel toalha descartável (IDEM).

A manutenção dos animais em ambientes higiênicos, secos e confortáveis visa em primeiro lugar amenizar os problemas relativos às mastites ambientais, mas indiretamente tem reflexo nos índices de mastite contagiosa. Animais com úberes sujos exigem cuidados redobrados por ocasião da ordenha. Deve-se observar com cautela às instalações para vacas secas, novilhas e vacas em lactação como piquetes, sombreamento, dimensão correta das instalações nos diferentes sistemas de confinamento, natureza da cama e baias ou piquetes de parição (SANTOS, 2002, p. 212).

Segundo a Lei de Diretrizes e Bases do Ministério da Agricultura e Desenvolvimento após a ordenha é necessário desinfetar as tetas com produto à base de iodo glicerinado 0,5 a $1 \%$, clorexidine 0,5 a 1\%, hipoclorito a 4\% ou ácido sulfônico a 1,94 \% (RIBEIRO e BRITO, 2012).

\subsection{Programa de Extensão Rural}

Este programa tem o objetivo de melhorar a formação de profissionais capazes de interpretar e agir não apenas na dimensão técnica, mas também nas dimensões econômica, social, cultural e ambiental, permitindo a solidez de competências e habilidades para a compreensão da realidade afetada pelos novos projetos de desenvolvimento.

A ideia de desenvolvimento envolve dois processos diferentes: crescimento e mudança. $\mathrm{O}$ crescimento pode ser visto sob o ponto de vista social e econômico na medida em que há um aumento na riqueza de um país, mas a mudança só ocorre quando mudam os padrões de distribuição da mesma. Neste contexto, não é difícil entender a importância da Extensão Rural, conforme afirma Bezerra, Sanchez e Ulrich apud Campelo (2011, p.126): 
agrícolas e melhoria das condições de vida da população rural (Bezerra, Sanchez e Ulrich 2011, apud CAMPELO, 1970).

Segundo Olinguer (2006), extensão rural é o processo de estender, à população rural, conhecimentos, habilidades e práticas agropecuárias, florestais e domésticas, reconhecidas como necessárias à melhoria de sua qualidade de vida.

\subsection{Mastite}

A mastite bovina é considerada a doença que acarreta os maiores prejuízos econômicos à produção leiteira, pela redução da quantidade e pelo comprometimento da qualidade do leite produzido, ou até pela perda total da capacidade secretora da glândula mamária.

Caracteriza-se por uma inflamação da glândula mamária, geralmente de caráter infeccioso, podendo ser classificada como clínica ou subclínica. A mastite ocasiona modificações patológicas no tecido glandular e uma série de alterações físicas e químicas do leite e merece destaque em virtude de causar prejuízos relacionados ao descarte do produto, queda na produção gastos com antibióticos e, eventualmente, o descarte do animal (BRITO e BRITO, 1998).

A mastite clínica apresenta sinais evidentes, tais como: edema, aumento de temperatura, endurecimento, dor na glândula mamária, grumos, pus ou qualquer alteração das características do leite (FONSECA \& SANTOS, 2000). Na forma subclínica não se observam alterações macroscópicas e sim alterações na composição do leite; portanto, não apresenta sinais visíveis de inflamação do úbere (CULLOR et al., 1994)

Na patogenia dessa doença, o organismo responde com o envio de leucócitos para o local, o que eleva a contagem de células somáticas (CCS) e afeta a composição do leite (PAULA et al., 2004).

Segundo Bouchot et al (1995), o diagnóstico da mastite clínica é realizado pelos sinais clínicos como inflamação do úbere, secreção láctea com grupos pus ou sangue. Enquanto a mastite subclínica é diagnosticada por exames baseados no conteúdo celular do leite. (COSTA, 1998).

Um dos testes que pode detectar a mastite subclínica é a contagem direta ou indireta de células somáticas no leite. Células somáticas são todas as células presentes no leite, que incluem as células originárias da corrente sanguínea como leucócitos e células de descamação do epitélio glandular secretor. Os leucócitos, em sua maioria, são mobilizados da corrente sanguínea para o tecido mamário diante de alterações na permeabilidade capilar. $\mathrm{O}$ aporte destas células se intensifica na quarta semana pré-parto, diminuindo gradativamente até uma semana pós-parto. $\mathrm{Na}$ secreção láctea de vacas com infecção intramamária, ocorre um aumento no número de células de defesa passando a predominar neutrófilos, seguidos por macrófagos, linfócitos e o número de células epiteliais permanece inalterado (PHILPOT e NICKERSON, 1991).

A contagem de células somáticas do leite indica, de maneira quantitativa, o grau de infecção da glândula mamária (MACHADO, PEREIRA, SARRIES, 2000).

O Somaticell@ é um teste qualitativo em essência, mas apresenta uma conversão para valores quantitativos, oferece um limite de resultados entre 69.000 a $1.970 .000 \mathrm{cel} / \mathrm{mL}$. Segundo Bordolla (2007), o Somaticell® é um indicador da CCS do leite, sendo utilizado no diagnóstico de vacas com mastite subclínica em programas de gerenciamento da mastite em rebanhos leiteiros e no gerenciamento da qualidade do leite do rebanho através da análise do leite dos tanques de expansão ou latões.

O Califórnia Mastitis Test (CMT) é um dos testes mais usuais para o diagnóstico da mastite subclínica, sendo um indicador indireto da contagem de células somáticas no leite. Este consiste na coleta do leite dos quartos mamários, individualmente, em uma bandeja apropriada, adicionando-se um detergente aniônico neutro, que atua rompendo a membrana das células e liberando o material nucléico (DNA), que apresenta alta viscosidade. De acordo com a intensidade 
da reação, classifica-se em: negativa $(0)$, reação leve $(+)$, moderada $(++)$ e intensa $(+++)$ (FONSECA \& SANTOS, 2000).

O sistema agroindustrial do leite é um dos mais importantes do país. A atividade é praticada em todo o território nacional em mais de um milhão de propriedades rurais e, somente na produção primária, gera acima de três milhões de empregos e agrega mais de seis bilhões ao valor da produção agropecuária nacional. (VILELA et al., 2002).

O município de Itaperuna caracteriza-se por ter um grande número de propriedades leiteiras com pequeno número de matrizes em seus rebanhos sendo o maior produtor da região Noroeste do estado do Rio de Janeiro tendo, assim, a produção de leite como uma atividade geradora de emprego e renda, sendo socialmente importante para a região.

Dessa forma, este trabalho visou realizar o levantamento de dados através da avaliação da qualidade do leite na cidade de Itaperuna, comparando resultados encontrados nos testes de CMT e Somaticell do leite de vacas de uma propriedade do município.

\section{Materiais e Métodos}

O presente trabalho pesquisou vacas com mastite subclínica com emprego do Califórnia Mastite (CMT) e teste de contagem de células somáticas no município de Itaperuna.

Durante as visitas, o proprietário foi informado sobre a intenção de realizar uma pesquisa, assim como seus objetivos, justificativa e hipótese, onde o mesmo aceitou participar.

A partir da autorização do proprietário, o mesmo recebeu orientação e informações a respeito do manejo do rebanho, da ordenha e dos principais fatores causadores de mastite, a importância de um manejo adequado, antes, durante e após a ordenha e sobre os testes que seriam realizados.

Foram avaliadas vacas, que são ordenhadas manualmente pelo próprio produtor.

A equipe do projeto de extensão rural da Universidade Iguaçu Campus V Itaperuna -RJ e os responsáveis pela pesquisa chegaram à propriedade no mesmo horário em que o produtor realizava a ordenha.

O material era coletado para análise imediatamente após cada ordenha, de maneira individual. Para cada vaca ordenhada era coletado um frasco pequeno de leite, uma parte desse leite era testado na propriedade imediatamente para a realização do teste de CMT e outra parte armazenada em recipiente, para realização do teste de Somaticell no laboratório da Universidade Iguaçu Campus V Itaperuna -RJ.

O teste de CMT (Califórnia Mastite Teste) foi realizado durante uma ordenha do mês de setembro e uma ordenha no mês de outubro.

Em setembro foram ordenhadas e avaliadas nove vacas e no mês de outubro tinham treze vacas. A inspeção é realizada visualmente avaliando a viscosidade do leite após a reação química entre leite e reagente.

O teste laboratorial, Somaticell foi realizado conforme as instruções do fabricante pela veterinária do laboratório de análises químicas da Universidade.

\section{Resultados e Discussão}

Amostras de leite de treze vacas, identificadas sequencialmente, foram submetidas aos testes de CMT e Somaticell no mês de setembro e outubro do ano de 2016, visando acompanhar a evolução ou não da mastite em tais animais. Os resultados foram registrados em tabelas apresentadas a seguir. 
ACTA

Biomedica Brasiliensia

Tabela 1: Comparação CTM e Somaticell - Análise em: 21/10/2016

\begin{tabular}{|c|c|c|c|c|c|c|c|}
\hline $\mathbf{N}^{\circ}$ da amostra & Identificação & $\begin{array}{c}\text { Resultado CMT } \\
\text { (Setembro) }\end{array}$ & $\begin{array}{c}\mathrm{N}^{\circ} \text { de quartos } \\
\text { positivos }\end{array}$ & $\begin{array}{l}\text { Resultado Somaticell } \\
\text { (ccsx1000/ml) } \\
\text { (Setembro) }\end{array}$ & $\begin{array}{c}\text { Resultado CMT } \\
\text { (Outubro) }\end{array}$ & $\begin{array}{l}\mathrm{N}^{\circ} \text { de quartos } \\
\text { positivo }\end{array}$ & $\begin{array}{l}\text { Resultado Somaticell } \\
\text { (ccsx1000/ml) } \\
\text { (Outubro) }\end{array}$ \\
\hline 01 & Dica & Negativo & 0 & Entre 69 a 79 & $\mathrm{~N} / \mathrm{E}$ & $\mathrm{N} / \mathrm{E}$ & $\mathrm{N} / \mathrm{E}$ \\
\hline 02 & Sabiá & Traços & 0 & Entre 89 a 98 & ++ & 1 & Entre 69 a 79 \\
\hline 03 & Paquita & Traços & 0 & Entre 98 a 108 & Traços & 0 & Entre 89 a 98 \\
\hline 04 & Croma & Traços & 0 & Entre 89 a 98 & Traços & 0 & Entre 166 a 186 \\
\hline 05 & Bolinha & +++ & 1 & Entre 244 a 263 & Mastite Clínica & 0 & Entre 457 a 470 \\
\hline 06 & Zazá & Traços & 0 & Entre 79 a 89 & $\mathrm{~N} / \mathrm{E}$ & $\mathrm{N} / \mathrm{E}$ & $\mathrm{N} / \mathrm{E}$ \\
\hline 07 & Catucha & $++/+++$ & 2 & Entre 500 a 530 & +++ & 2 & Entre 760 a 800 \\
\hline 08 & Boneca & + & 1 & Entre 98 a 108 & ++ & 1 & Entre 321 a 340 \\
\hline 09 & Adriana & +++ & 1 & Entre 224 a 244 & +++ & 2 & Entre 418 a 457 \\
\hline 10 & Tere & N/E & $\mathrm{N} / \mathrm{E}$ & $\mathrm{N} / \mathrm{E}$ & Traços & 0 & Entre 79 a 89 \\
\hline 11 & Lancha & $\mathrm{N} / \mathrm{E}$ & $\mathrm{N} / \mathrm{E}$ & $\mathrm{N} / \mathrm{E}$ & Traços & 0 & Entre 89 a 98 \\
\hline 12 & Rolinha & $\mathrm{N} / \mathrm{E}$ & $\mathrm{N} / \mathrm{E}$ & $\mathrm{N} / \mathrm{E}$ & Traços & 0 & Entre 457 a 470 \\
\hline 13 & Argentina & N/E & $\mathrm{N} / \mathrm{E}$ & $\mathrm{N} / \mathrm{E}$ & +++ & 4 & Entre 630 a 700 \\
\hline
\end{tabular}

(Legenda: N/E: Não Executado; Intensidade: Traços,,,$+++++/+++,+++)$. 


\section{Biomedica Brasiliensia}

Na Tabela 1, é possível observar que o animal da amostra 2, no primeiro momento, apresentava resultado negativo tanto no teste de CMT (Traços), quanto no teste Somaticell. No segundo momento do teste, houve uma progressão do quadro de mastite indicada pelo resultado do método de CMT apresentando um achado positivo (++) em um quarto mamário, porém não evidenciado o mesmo padrão de elevação pelo resultado do Somaticell que apresentou um valor abaixo do encontrado no primeiro teste realizado. Tal fato pode ser justificado pela questão de ser um teste qualitativo e depender da interpretação do profissional executor.

Nos animais das amostras 3 e 4, verificou-se uma constante dos resultados em ambos os testes realizados nos dois momentos das análises. Já na amostra 5, nos primeiros testes foram obtidos resultados positivos indicando ocorrência de mastite subclínica, e posteriormente nos testes seguintes evolui para um quadro sugestivo de mastite clínica.

A amostra 7, apresentou resultados compatíveis com mastite subclínica para o teste CMT em 2 (dois) quartos mamários, comum a ligeira variação na intensidade de positividade $(++/+++)$ destes testes de um quarto para o outro nos resultados, e reproduzindo a positividade (+++) nos testes realizados na segunda etapa de análises no mês seguinte avaliado. $\mathrm{O}$ animal referente a amostra número 8 apresentou resultados progressivos em ambos os testes, sugerindo a ocorrência de quadro de mastite subclínica em evolução.

$\mathrm{Na}$ amostra 9 houve uma constante no resultado, sendo este positivo no teste de CMT. Já nos achados do teste do Somaticell, houve um aumento entre a primeira análise para a segunda realizada, e também um aumento no número de quartos mamários acometidos segundo os resultados encontrados com o teste CMT.

Os animais das amostras de número 10,11, 12 e 13 não foram analisados no primeiro mês de execução do teste por não se encontrarem em período e lactação. No mês de outubro os achados dos testes nas amostras 10 e 11 demonstram quartos mamários saudáveis segundo os resultados obtidos com os testes realizados. Já amostra 12, não foi observada compatibilidade no resultado entre os testes CMT que apresentou resultado negativo, e o Somaticell apresentava resultadocompatívelcom um processo patológico em grau moderado. $\mathrm{O}$ animal da amostra 13 foi evidenciado resultado positivo em ambos os testes com a observação de achados proporcionais nos dois métodos e apresentando os 4 (quatro) quartos mamários acometidos.

$\mathrm{Na}$ Figura 1, constam os dados registrados dos testes de CMT realizados nos dois momentos de análise, quanto à identificação dos quartos mamários avaliados e os resultados respectivos.

\begin{tabular}{|c|c|c|c|c|c|c|c|c|c|c|c|c|c|c|c|c|c|c|c|c|c|c|c|c|c|}
\hline \multicolumn{26}{|c|}{ Anotação de resultado o teste de CMT } \\
\hline \multicolumn{13}{|l|}{$\begin{array}{l}\text { Produtor: } \\
\text { Fazenda: }\end{array}$} & \multicolumn{13}{|c|}{$\begin{array}{l}\text { Localização: } \\
\text { Ano: }\end{array}$} \\
\hline \multicolumn{26}{|c|}{ Resultados do teste CMT } \\
\hline Mês & \multicolumn{4}{|c|}{ Julho } & \multicolumn{4}{|c|}{ Agosto } & \multicolumn{4}{|c|}{ Setembro } & \multicolumn{4}{|c|}{ Outubro } & \multicolumn{4}{|c|}{ Novembro } & \multicolumn{4}{|c|}{ Dezembro } & Anotações \\
\hline \multirow{2}{*}{$\begin{array}{l}\text { Identificação } \\
\text { da vaca }\end{array}$} & \multicolumn{4}{|c|}{ Resultado do teste } & \multicolumn{4}{|c|}{ Resultado do teste } & \multicolumn{4}{|c|}{ Resultado do teste } & \multicolumn{4}{|c|}{ Resultado do teste } & \multicolumn{4}{|c|}{ Resultado do teste } & \multicolumn{4}{|c|}{ Resultado do teste } & \\
\hline & $A D$ & $\mathrm{PD}$ & $\mathrm{AE}$ & $\mathrm{PE}$ & $A D$ & $\mathrm{PD}$ & $\mathrm{AE}$ & $\mathrm{PE}$ & $A D$ & PD & $\mathrm{AE}$ & $\mathrm{PE}$ & $A D$ & $\mathrm{PD}$ & $\mathrm{AE}$ & $\mathrm{PE}$ & $A D$ & PD & $\mathrm{AE}$ & $\mathrm{PE}$ & $A D$ & $\mathrm{PD}$ & $\mathrm{AE}$ & $\mathrm{PE}$ & \\
\hline 02 & & & & & & & & & - & - & - & - & - & - & - & ++ & & & & & & & & & \\
\hline 03 & & & & & & & & & - & - & - & - & - & - & - & - & & & & & & & & & \\
\hline 04 & & & & & & & & & - & - & - & - & - & - & - & - & & & & & & & & & \\
\hline 05 & & & & & & & & & - & - & - & +++ & - & - & - & MC & & & & & & & & & \\
\hline 06 & & & & & & & & & - & - & - & - & & & & & & & & & & & & & \\
\hline 07 & & & & & & & & & +++ & +++ & - & - & +++ & +++ & - & - & & & & & & & & & \\
\hline 08 & & & & & & & & & - & - & - & + & - & - & - & ++ & & & & & & & & & \\
\hline 09 & & & & & & & & & - & - & +++ & - & +++ & - & +++ & - & & & & & & & & & \\
\hline 10 & & & & & & & & & & & & & - & - & - & - & & & & & & & & & \\
\hline 11 & & & & & & & & & & & & & - & - & - & - & & & & & & & & & \\
\hline 12 & & & & & & & & & & & & & - & - & - & - & & & & & & & & & \\
\hline 13 & & & & & & & & & & & & & +++ & +++ & ++++ & ++++ & & & & & & & & & \\
\hline
\end{tabular}

Figura 1: Ficha de Anotação de Mastite Subclínica. Legenda: AD: Anterior Direito, PD: Posterior Direito, AE: Anterior Esquerdo, PE: Posterior Esquerdo, MC: Mastite Clínica; $\quad$ Intensidade: -, Traços, +, ++, +++.

Fonte: Autor. 
Os dados apresentados na Figura 1 sugerem uma evolução do quadro de mastite nos animais das amostras de números 2, 5, 8 e 9.

A Tabela 2 apresenta os valores da análise físico-química do leite e do teste de CCS, visto que a mastite é uma condição patológica que pode causar alterações na composição do leite.

Através da análise dos dados apresentados na Tabela 2, foi observado que não houve um padrão significativo de alterações nos valores dos componentes das amostras, mesmo em animais com resultados positivos no teste de CCS.

Correlacionando os achados observados nos resultados do teste de CMT e do teste Somaticell, nos dois momentos de análise, encontramos que, no primeiro mês do trabalho, cinco (5) amostras foram positivas ao teste Somaticell, contrapondo a quatro (4) amostras positivas no teste de CMT.

No segundo mês do experimento, os achados observados consistem no número de seis (6) amostras positivas no teste CMT, sendo uma delas proveniente de um animal que apresentava mastite clínica. E no teste Somaticell, um número de sete (7) amostras positivas, mantendo assim, a variação nos resultados de ambos os métodos nos dois momentos de análises.

Essa correlação corrobora com os resultados obtidos por Medeiros et al (2008), que em seu estudo, encontraram que a maioria das amostras analisadas foi positiva nos dois testes e, que nas amostras não coincidentes, um maior número apresentou resultado positivo no teste Somaticell e negativo ao CMT.

Langoni et al (2012), constataram em seu trabalho, onde também apresenta uma comparação entre os testes CMT e Somaticell, que, principalmente em plataformas de leite, o CMT pode ser deficiente devido à subjetividade na sua interpretação e que, por esse motivo, o teste Somaticell pode revelar-se como uma importante ferramenta a ser usada nesses casos.

Evidencia-se neste trabalho um número alto de resultados positivos para mastite subclínica em ambos os testes, o que, devido às circunstâncias da propriedade avaliada, a qual realiza ordenha manual, sem implementação tecnológica e de estratégias de boas práticas de ordenha, já era esperado.

Assim como apresentam Philpot e Nickerson (2002), em estudos feitos em Minnesota, onde revelaram que $80 \%$ dos rebanhos com contagem de células somáticas elevadas não seguiam os procedimentos de ordenha recomendados. $\mathrm{O}$ erro mais comum era a falha em limpar e secar os tetos corretamente antes de realizar a ordenha.

Pedrini et al (2003), descreveram que o desenvolvimento de programas no controle da mastite implica em medidas como, tratamento de vacas no período seco, tratamento dos casos clínicos, manejo adequado e bom funcionamento do sistema de ordenha.

Medidas como a lavagem dos tetos com água corrente e secagem com papel toalha reduzem o número de bactérias nas superfícies dos tetos, mas tornou-se mais eficiente com a utilização de antissépticos (iodo ou toalha com clorexidine), principalmente em casos que se utiliza o bezerro para a descida do leite durante a ordenha (BRITO et al,2000).

O tratamento com desinfetantes à base de iodo, clorexidine e cloro (hipoclorito de sódio), são comumente utilizados nas propriedades rurais para o controle de população de microorganismos dos tetos nas ordenhas, diminuindo no pré-dipping a contaminação, reduzindo em até 50\% a taxa de novas infecções causadas por patógenos (SANTOS e FONSECA, 2007).

Matsubaraet al concluíram que as boas práticas de ordenha demonstraram ser suficientes para adequar o leite produzido aos parâmetros estabelecidos pela Instrução Normativa 51.

Paola (2005) avaliaram em quatro propriedades rurais o efeito de diferentes técnicas profiláticas de higiene e limpeza, durante o manejo de produção, na qualidade bacteriológica do leite através da contagem de bactérias psicotróficas. Os dados demonstraram que após a adoção das técnicas de profiláticas, ocorreram diminuições significativas na contagem de bactérias psicotróficas do leite em todas as propriedades rurais estudadas, comprovando a importância das práticas preventivas de higiene e limpeza sobre a qualidade bacteriológica do leite. 
ACTA

Biomedica Brasiliensia

ISSN: 2236-0867

Tabela 2: Análise Físico-química do Leite.

\begin{tabular}{|c|c|c|c|c|c|c|c|c|c|c|c|}
\hline Amostra & CCS & Gordura & SNG & Densidade & Proteína & Lactose & Sais & $\begin{array}{c}\text { Água } \\
\text { adicionada }\end{array}$ & $\begin{array}{c}\text { Ponto } \\
\text { Congelamento }\end{array}$ & pH & Condutividade \\
\hline 01 & $\mathrm{~N} / \mathrm{E}$ & $\mathrm{N} / \mathrm{E}$ & $\mathrm{N} / \mathrm{E}$ & $\mathrm{N} / \mathrm{E}$ & $\mathrm{N} / \mathrm{E}$ & $\mathrm{N} / \mathrm{E}$ & $\mathrm{N} / \mathrm{E}$ & $\mathrm{N} / \mathrm{E}$ & $\mathrm{N} / \mathrm{E}$ & $\mathrm{N} / \mathrm{E}$ & $\mathrm{N} / \mathrm{E}$ \\
\hline 02 & Entre 69 a 79 & 3,3 & 8,80 & 31,6 & 3,2 & 4,8 & 0,7 & 0,0 & $-0,562$ & 6,6 & 5,9 \\
\hline 03 & Entre 89 a 98 & 2,8 & 8,64 & 31,4 & 3,1 & 4,7 & 0,7 & 0,0 & $-0,547$ & 6,6 & 6,0 \\
\hline 04 & Entre 166 a 186 & 1,0 & 8,14 & 30,9 & 2,9 & 4,4 & 0,6 & 0,0 & $-0,502$ & 6,5 & 5,1 \\
\hline 05 & Entre 457 a 470 & 2,2 & 8,37 & 30,8 & 3,0 & 4,6 & 0,6 & 0,0 & $-0,525$ & 6,4 & 5,1 \\
\hline 06 & N/E & $\mathrm{N} / \mathrm{E}$ & $\mathrm{N} / \mathrm{E}$ & $\mathrm{N} / \mathrm{E}$ & $\mathrm{N} / \mathrm{E}$ & $\mathrm{N} / \mathrm{E}$ & $\mathrm{N} / \mathrm{E}$ & $\mathrm{N} / \mathrm{E}$ & $\mathrm{N} / \mathrm{E}$ & $\mathrm{N} / \mathrm{E}$ & $\mathrm{N} / \mathrm{E}$ \\
\hline 07 & Entre 760 a 800 & 3,4 & 8,67 & 31,0 & 3,1 & 4,7 & 0,7 & 0,0 & $-0,554$ & 6,6 & 5,0 \\
\hline 08 & Entre 321 a 340 & 4,0 & 8,90 & 31,5 & 3,2 & 4,9 & 0,7 & 0,0 & $-0,574$ & 6,5 & 5,0 \\
\hline 09 & Entre 418 a 457 & 4,1 & 9,02 & 31,9 & 3,3 & 4,9 & 0,7 & 0,0 & $-0,584$ & 6,6 & 5,9 \\
\hline 10 & Entre 79 a 89 & 2,1 & 9,17 & 34,0 & 3,3 & 5,0 & 0,7 & 0,0 & $-0,580$ & 6,4 & $-2,0$ \\
\hline 11 & Entre 89 a 98 & 3,2 & 8,79 & 31,7 & 3,2 & 4,8 & 0,7 & 0,0 & $-0,560$ & 6,2 & 5,1 \\
\hline 12 & Entre 457 a 470 & 4,1 & 9,44 & 33,5 & 3,4 & 5,2 & 0,7 & 0,0 & $-0,614$ & 6,2 & 5,9 \\
\hline 13 & Entre 630 a 700 & 3,6 & 8,67 & 30,9 & 3,1 & 4,7 & 0,7 & 0,0 & $-0,555$ & 6,9 & 4,8 \\
\hline
\end{tabular}

Legenda: N/E: Não Executado. 
Hoe e Soriano (2006) afirmam que os procedimentos na rotina de ordenha necessários para prevenção de mastite podem ser enumerados sequencialmente:

- Estimulação pré-ordenha.

- Ambiente limpo, seco e livre de estresse.

- Checagem da presença de mastite (retirando os primeiros jatos de leite).

- Limpeza dos tetos e retirada de areia ou maravalha do úbere.

- Uso de pré-dipping (desinfecção dos tetos pré-ordenha).

- Cuidado especial com a ponta do teto

- Retirada do desinfetante e completa secagem dos tetos

- Acoplamento das teteiras corretamente.

- Posicionamento do conjunto (alinhar).

- Retirada conjunto manual ou extrator.

- Realização de um bom pós-dipping (boa imersão dos testos pós-ordenha). de ordenha.

- Desinfecção da teteira após ordenha de vacas com mastite, caso estejam na mesma sala

Os responsáveis pela propriedade avaliada no presente trabalho foram orientados quanto aos procedimentos acima citados, porém foi constado que nem todos os passos necessários foram seguidos, o que justifica o resultado encontrado do número de casos positivos nos animais analisados.

Silva e Nogueira (2010) salientam que o programa de manejo de ordenha não possui um padrão. Desta maneira, deve ser adequado com a realidade de cada propriedade e ter uma integração de todos os funcionários responsáveis.

\section{Conclusão}

A qualidade do leite é diretamente influenciada pelo controle e profilaxia da mastite clínica e subclínica e pelas medidas de boa prática de ordenha e manejo.

Os métodos rápidos e práticos de diagnóstico são necessários para monitoramento do leite e, tanto o teste CMT quanto o teste Somaticell são eficazes para tal fim, sendo que o último teste citado apresenta uma sensibilidade maior e interpretação menos subjetiva quando comparado ao CMT.

Além disso, constatou-se a importância da orientação e da realização da prática do prédipping e pós-dipping, conforme às diretrizes estabelecidas pelo órgão regulamentador do controle de qualidade, visto que por falhar em tais procedimentos, a propriedade avaliada apresentou evolução no quadro de mastite subclínica em seus animais.

\section{Referências}

BORDOLLA, C.C. Métodos de detección de lasmastitis bovina. Revista Eletrônica de Veterinária, 2007. v.8, n.9, p.1-17

BRITO, J. R. F; BRITO, M. A. V. P.; VERNEQUE, R. S. Contagem bacteriana da superfície de tetas de vacas submetidas a diferentes processos de higienização incluindo a ordenha manual com participação do bezerro para estimular a descida do leite. Ciência Rural, Santa Maria, 2000 v. 30, n. 5 , p. $847-850$.

CULLOR, J. S., TYLER, J. W., SMITH, B. P. Distúrbios da glândula mamária. In: SMITH, B.

P. Tratado de Medicina Interna dos Grandes Animais. São Paulo, 1994, v.2, p.1041-1060. 
FONSECA, L. F. L.; SANTOS, M. V. Qualidade do Leite e Controle de Mastite. Lemos Editorial, 175p. São Paulo, 2000.

HOE, F. G. H., SORIANO, S. O que um técnico deve conhecer sobre a prevenção de mastite. In: MESQUITA, A. J., DURR J. W., COELHO, K. O. Perspectivas e avanços da qualidade do leite no Brasil. Goiânia, 2006.: Talento, v.1, p.107-118.

LANGONI et al. Avaliação do Somaticell@ como método de triagem para contagem de células somáticas do leite de bovinos. Ciência Rural, Santa Maria jun, 2012.v.42, n.6, p.1095-1101.

MATSUBARA M. T. et al. Boas práticas de ordenha para redução da contaminação microbiológica do leite no agreste Pernambucano. Seminario: Ciências Agrárias, Londrina, jan./mar. 2011. v. 32, n. 1, p. 277-286.

MEDEIROS et al. Avaliação do exame microbiológico, California Mastitis Test e Somaticell@ no diagnóstico da mastite subclínica em bovinos leiteiros Medicina Veterinária, Recife,abr-jun, 2008, v.2, n.2, p.16-22.

PAOLA K. G.; MÁRCIA R. F. M.; GILBERTO C. B.; ELIANE G.; ALEXANDRA S. M. F. Qualidade microbiológica de leite em função de técnicas profiláticas no manejo de produção. Revista de Ciência e Agrotecnologia. Lavras, v. 29, n. 1 Jan/Feb. 2005.

PEDRINI, S. C. B.; MARGATHO, L. F. F. Sensibilidade de microorganismos patogênicos isolados de casos de mastite clínica em bovinos frente a diferentes tipos de desinfetantes. Arquivos do Instituto Biológico. São Paulo,2003. v. 70, n. 4, p. 391-395.

PHILPOT, W. N.; NICKERSON, S. C. Mastitis: Counter Attack. A strategy to combat mastitis. Illinois: Babson Brothers Co., 1991. 150p.

PHILPOT, W. N.; NICKERSON, S. C. Vencendo a luta contra a mastite, 2002.p. 02-05, p.2227, p. 54-81.

SILVA, M. V. M.; NOGUEIRA, J. L. Mastite: controle e profilaxia no rebanho bovino. Revista Científica Eletrônica de Medicina Veterinária, Ano VII, Número 15, Periódico Semestral, 2010.

VILELA, D.; LEITE, J. L. B.; RESENDE, J. C. Políticas para o leite no Brasil: passado presente e futuro. In: Santos, G. T.; Jobim, C. C.; Damasceno, J. C. Sul Leite Simpósio sobre Sustentabilidade da Pecuária Leiteira na Região Sul do Brasil, 2002, Maringá. Anais... Maringá: UEM/CCA/DZO-NUPEL, 2002. 